\title{
Cause of maximum pain in hospitalized children and adolescents - A pilot project
}

\author{
Teresa Heitzeneder ${ }^{1 *}$, Andreas Sandner-Kiesling ${ }^{1}$, Alexander Avian², Brigitte Messerer ${ }^{1}$ \\ From Safety in hospitals: from strategy to implementation Annual Scientific Meeting 2015 \\ Graz, Austria. 29-30 September 2015
}

\section{Background}

In recent years, much has been achieved in interdisciplinary cooperation concerning pain management and pain therapy with children and adolescents [1]. Key points were the age-appropriate assessment of pain at rest, on movement and maximum pain and their adequate treatment [2]. But there exist only few data concerning the reasons for maximum pain in children and adolescents $[3,4]$. This pilot study investigates this issue in children and adolescents from admission to discharge.

\section{Material and methods}

For this exploratory pilot study, children and adolescents aged 11-18 years, which had a surgical intervention at the Department of Paediatric and Adolescent Surgery of the University of Graz, were interviewed by using a semistructured interview guide. A descriptive analysis of the frequency of reported causes for the maximum pain and an examination of the relationships between the different types of surgery and the maximum pain followed.

\section{Results}

A total of 41 patients were included in this study. The most common reasons of maximum pain was the preoperative period $(\mathrm{n}=8)$, followed by preoperative manual examinations $(\mathrm{n}=4)$ and the first mobilization attempts postoperatively $(\mathrm{n}=4)$. The most frequent and painful surgery were appendectomy $(n=9)$, followed by knee arthroscopy and surgeries $(n=6)$. Osteosyntheses of upper limb fractures were less painful.

\section{Conclusions}

The reasons for maximum pain regarding different types of surgery found in adults and children/adolescents, could be also confirmed in children and young people aged 11-18 years. The preoperative period as well as the preoperative manual examinations and the first mobilization attempts postoperatively represent new approaches for a future closer research.

\section{Competing interests}

There is no conflict of interest.

\section{Authors' details}

${ }^{1}$ Department of Anesthesiology and Intensive Care Medicine, Medical University of Graz, Austria. ${ }^{2}$ Institute for Medical Informatics, Statistics and Documentation, Medical University of Graz, Austria.

Published: 30 October 2015

\section{References}

1. Messerer B, Sandner-Kiesling A: Organization of pediatric pain management: Austrian interdisciplinary recommendations for pediatric perioperative pain management. Schmerz 2014, 28(1):14-24.

2. Messerer B, Gutmann A, Vittinghoff $M$, et al: Postoperative pain assessment in special patient groups: part I+II. Schmerz 2011, 25(3):245-65.

3. Balga I, Konrad C, Meissner W: Postoperative Qualitätsanalyse bei Kindern: Schmerz sowie postoperative Übelkeit und Erbrechen. Anaesthesist 2013, 62:707-19.

4. Stewart DW, Ragg PG, Sheppard S, et al: The severity and duration of postoperative pain and analgesia requirements in children after tonsillectomy, orchidopexy, or inguinal hernia repair. Paediatr Anaesth 2012, 22:136-43.

\section{doi:10.1186/2056-5917-1-S1-A3}

Cite this article as: Heitzeneder et al:: Cause of maximum pain in hospitalized children and adolescents - A pilot project. Safety in Health 2015 1(Suppl 1):A3.

\footnotetext{
* Correspondence: heitzeneder_teresa@gmx.at

'Department of Anesthesiology and Intensive Care Medicine, Medical

University of Graz, Austria

Full list of author information is available at the end of the article
} 